\title{
BMJ Global Health Factors influencing inappropriate use of antibiotics in outpatient and community settings in China: a mixed-methods systematic review
}

\author{
Leesa Lin (10 , ${ }^{1}$ Ruyu Sun, ${ }^{2}$ Tingting Yao, ${ }^{2}$ Xudong Zhou, ${ }^{2}$ Stephan Harbarth ${ }^{3,4}$
}

To cite: Lin L, Sun R, Yao T, et al. Factors influencing inappropriate use of antibiotics in outpatient and community settings in China: a mixed-methods systematic review. BMJ Global Health 2020;5:e003599. doi:10.1136/ bmjgh-2020-003599

Handling editor Seye Abimbola

Received 1 August 2020

Revised 2 September 2020

Accepted 8 September 2020

A Check for updates

(C) Author(s) (or their employer(s)) 2020. Re-use permitted under CC BY. Published by BMJ.

${ }^{1}$ Department of Infectious Disease Epidemiology, London School of Hygiene \& Tropical Medicine, London, UK ${ }^{2}$ Institute of Social Medicine, School of Medicine, Zhejiang University, Hangzhou, China ${ }^{3}$ Infection Control Programme, University of Geneva Hospitals and Faculty of Medicine, Geneva, Switzerland ${ }^{4}$ Infectious Diseases Division, University of Geneva Hospitals and Faculty of Medicine, Geneva, Switzerland

Correspondence to

Dr Leesa Lin;

leesa.lin@Ishtm.ac.uk

\section{ABSTRACT}

Background For decades, antibiotics have been excessively consumed around the world, contributing to increased antimicrobial resistance (AMR) and negatively impacting health outcomes and expenditures. Antibiotic use in China accounts for half of worldwide antibiotic consumption, which mainly takes place in outpatient and community settings, and often unnecessarily for self-limiting community-acquired infections. This study aimed to identify and assess factors of inappropriate use of antibiotics in the Chinese context to inform the development of interventions to mitigate inappropriate consumption in the absence of clinical indications. Methods We conducted a mixed-methods systematic review and included empirical studies with original data conducted in mainland China, Hong Kong and Taiwan that investigated factors of antibiotic use in the community including outpatient care among patients, caregivers and prescribers. We searched MEDLINE, EMBASE, the Cochrane Library, PsycINF0, Google Scholar and one Chinese database CNKI (China Knowledge Resource Integrated Database), using a combination of the key terms 'antibiotic', 'antimicrobial', 'use', 'consumption', 'behaviour', 'prescribe' and related syntax for all peerreviewed publications published before June 2020 . Health Belief Model was employed for data synthesis.

Findings Fifty-four studies were included in the full-text review: 44 quantitative, 5 qualitative and 5 mixed-methods studies. Despite a high AMR awareness, public perception/ misconception of antibiotic efficacy and easy access to antibiotics for self-limiting conditions drive inappropriate demand and use in the community including primary care setting. Providers' prescribing behaviours are influenced by financial incentives, lack of diagnostic capacity and concerns over complications.

Conclusions Inappropriate outpatient and community antibiotic use is influenced by non-biomedical factors at the individual, community, health system and societal levels in mainland China, contributing to a high antibiotic use rate. This study calls for context-tailored One Health interventions, restrictive antibiotic drug policy and multifaceted antibiotic stewardship programmes that simultaneously address drivers of inappropriate use from both the supply-side and demand-side within and beyond clinical settings.

PROSPERO registration number CRD42019139591.

\section{Key questions}

\section{What is already known?}

- Human use of antibiotics in China accounts for a quarter of worldwide antibiotic consumption, which mainly takes place in outpatient and community settings.

- Many of the antibiotic uses were inappropriate and often unnecessarily for self-limiting communityacquired infections.

What are the new findings?

- Inappropriate use of antibiotics is prevalent across China with significant regional variation influenced by non-biomedical factors within and beyond clinical settings.

- Multifaceted, interactive personal and environmental factors shape antibiotic use for both the supply-side and demand-side of China's healthcare system.

What do the new findings imply?

- Inappropriate antibiotic consumption is unlikely to decrease without multifaceted, context-tailored strategies targeting patients, prescribers and healthcare systems.

- Future strategies should incorporate an evidencebased, context-tailored design that simultaneously addresses drivers of antibiotic misuse from both the supply-side and demand-side within and beyond clinical settings.

\section{INTRODUCTION}

For decades, antibiotics have been excessively consumed around the world, contributing to increased antimicrobial resistance (AMR) and negatively impacting health outcomes and expenditures. ${ }^{1-3}$ Reducing inappropriate antibiotic use is a pressing global health priority. Human use of antibiotics in China accounts for a quarter of worldwide antibiotic consumption, ${ }^{4} 5$ which mainly takes place in outpatient and community settings, often unnecessarily for self-limiting community-acquired infections-mostly viral and non-complicated, and untreatable by 
antibiotics. ${ }^{56} \mathrm{~A}$ thorough examination of the prevalence of and factors influencing community antibiotic use in China is vital to inform the development of relevant policy and intervention strategies aiming to mitigate inappropriate or unnecessary antibiotic use, namely antibiotics consumed in the absence of clinical indications. This study aimed to conduct a mixed-methods systematic review that identifies and assesses factors influencing healthcare users' and providers' antibiotic use in the Chinese context.

\section{METHODS}

This mixed-methods review aimed to identify determinants for inappropriate antibiotic use in the community, including primary care and hospital outpatient settings, in Mainland China, Hong Kong and Taiwan. We systematically searched the following databases: MEDLINE, EMBASE, the Cochrane Library, and PsycINFO, Google Scholar and one Chinese database CNKI (China Knowledge Resource Integrated Database), using a combination of the key terms 'antibiotic', 'antimicrobial', 'use', 'consumption', 'behaviour', 'prescribe' and related syntax for all peer-reviewed publications published before June 2020.

As a primary outcome of interest, 'inappropriate antibiotic use' included unnecessary antibiotic use for selflimiting viral infections (treatment or prophylaxis), self-medication with antibiotics by consumers and unnecessary antibiotic prescriptions for self-limiting viral infections by providers. Relevant behaviour outcomes, such as household storage of antibiotics, over-the-counter purchases and demands for antibiotic prescriptions, were also identified. No restrictions were applied to language, populations or antibiotic use for specific medical conditions. The search strategy for each database is presented in online supplemental file S1. Studies that focused only on (1) knowledge, attitudes and beliefs with regard to antibiotic use or (2) antibiotic prescriptions analysis were excluded. For the quantitative component, data from cross-sectional and longitudinal studies, where relevant confounders were accounted for by the study design or analysis, were included. Qualitative studies where methods of data collection and analysis were explicitly reported were eligible for inclusion. Experiments that generated empirical data were included whereas nonempirical studies or studies not reporting original data were excluded. A full list of inclusion/exclusion criteria is presented in online supplemental file S2. In addition, we conducted manual searches of the reference lists of included studies to identify additional relevant studies. All citations identified were imported to Endnote, and duplicates were deleted. Two reviewers (LL and TY or RS) independently screened titles and abstracts to select potentially relevant citations. Articles included in the full text review stage were retrieved and independently scrutinised. Any discrepancies in the process were resolved through discussion with a third reviewer until consensus was reached (see figure 1).

A standardised form based on Cochrane Review and behavioural theories including the Health Belief $\mathrm{Model}^{7}$ and Social Ecological Framework ${ }^{8}$ was developed specifically for this review prior to data extraction. Data were double extracted by two reviewers (TY and RS). Employing the Health Belief Model, we aimed to identify factors that could explain and predict individual uptake of antibiotics while adopting the Socio Ecological Framework, we incorporated the complex interplay between individual, relationship, community and societal factors in our synthesis and analysis of data. ${ }^{9}$ Disagreements were discussed with a third reviewer (LL) and resolved through consensus. The information extracted included characteristics of the study, methods, target population, sample size, antibiotic use behaviours and associated factors influencing behaviours. Numerical data (numbers or percentages) that reported prevalence and non-medical factors of antibiotic use were extracted from the quantitative component; themes relevant to factors influencing antibiotic use behaviours were extracted for the qualitative component.

\section{Quality assessment of included studies}

Three reviewers (LL, TY, RS) independently assessed the risk of bias in all included studies using predetermined tools and reached consensus through discussion when discrepancies arose. The quantitative studies and quantitative components from mixed-methods studies that met inclusion criteria were assessed by adapted $B M J$ survey appraisal tools ${ }^{10}$; qualitative studies and the qualitative components from mixed-methods studies were appraised by the Critical Appraisals Skills Programme Appraisal Checklists ${ }^{11}$; experiments and mixed-methods studies were appraised by Mixed Methods Appraisal Tool. ${ }^{12}$ We followed the Preferred Reporting Items for Systematic Reviews and Meta-Analyses statement guidelines for reporting systematic reviews in structuring the review findings.

\section{Patient and public involvement statement}

Patient and public were not involved in this systematic literature review.

\section{RESULTS}

We identified 54 studies: 37 focused on the consumers of healthcare, 13 on providers and 4 on both, involving a total of 104619 participants. Table 1 summarised the characteristics of the included studies. We noted seven experiments employed the simulated client/patient method (SCM/SPM) to investigate factors influencing healthcare providers' antibiotic use and only one study took the One Health approach investigating associations between antibiotic use for human and animals (ie, farm pigs). Almost all studies ( $\mathrm{n}=53 ; 98.1 \%)$ employed crosssectional designs and all included adult participants, with some $(\mathrm{n}=9 ; 16.7 \%)$ specifically involving the parents of 


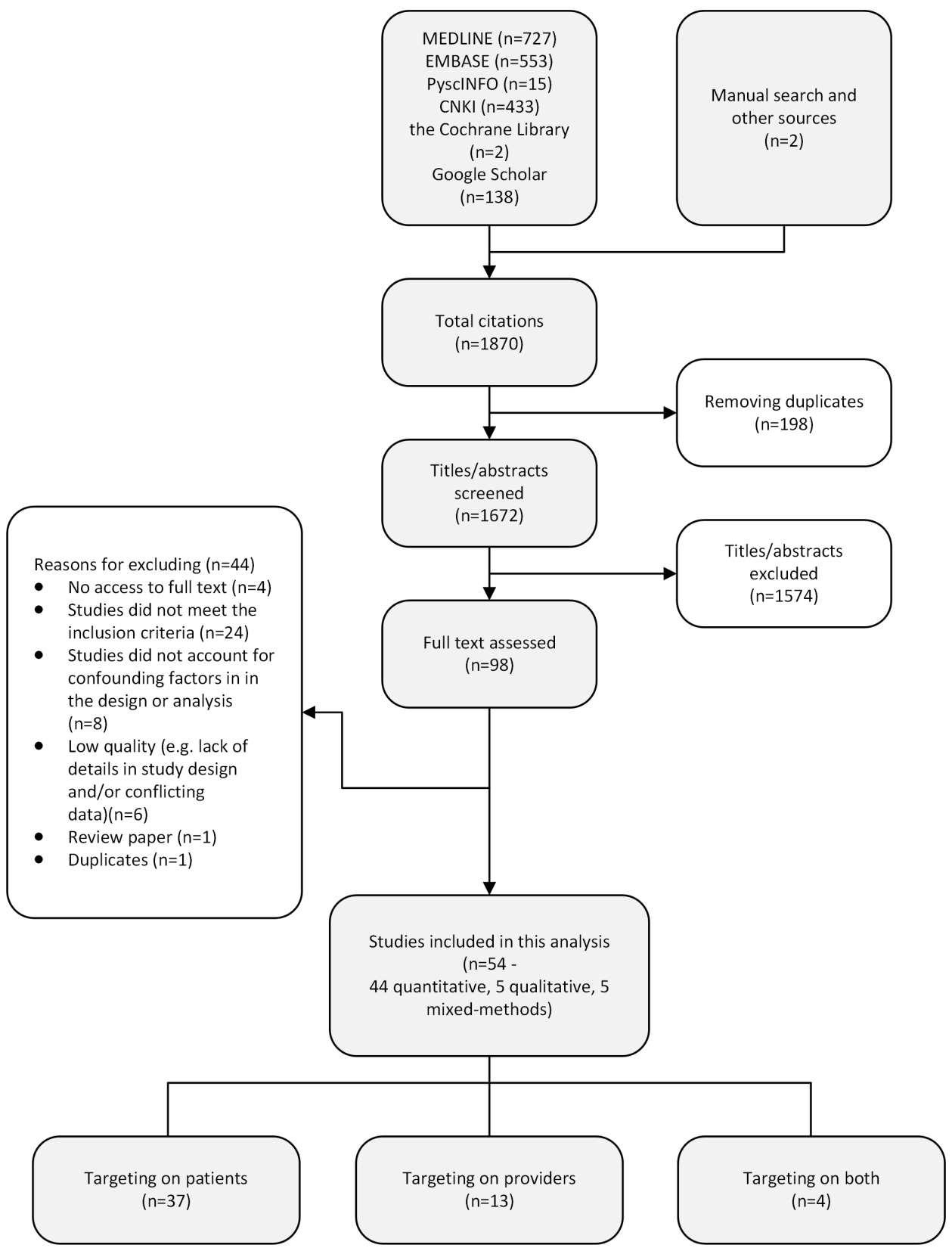

Figure 1 Flowchart of study identification and selection.

children. More than half $(n=30 ; 55.6 \%)$ of the included studies were published after 2016 . There were 44 quantitative (including 6 experiments), 5 qualitative and 5 mixedmethods studies (including 1 experiment). Nine studies were conducted in Hong Kong, one in Taiwan and the rest $(n=44)$ in mainland China, a majority covering both rural and urban settings. Little evidence about community antibiotic use was available from Taiwan. Identified non-biomedical factors of antibiotic use in the community were analysed and synthesised, presented in table 2 .

\section{Quantitative synthesis of factors influencing antibiotic use in the community}

In online supplemental file S3.1-3.22, we summarised the identified factors of antibiotic use, measures (eg, denominator, numerator and recall period) and geographic distributions of antibiotic use practices that have been studied across China. We found inconsistency in defining and measuring various types of antibiotic use behaviours, which raises issues of cross-study comparability and evaluation. A total of 49 studies quantitatively investigated factors influencing inappropriate antibiotic use either by patients, caregivers or providers within and beyond clinical settings. The synthesis of quantitative data on public antibiotic misuse behaviours in the community by study region is presented in figure 2 .

\section{Clinical settings}

Antibiotic prescriptions for presumed self-limiting illnesses

The likelihood of being prescribed with antibiotics for presumed self-limiting illnesses during an outpatient clinic visit varied from $53.3 \%{ }^{13}$ to $94.5 \%{ }^{14}$ in mainland China and 
BMJ Global Health

Table 1 Summary of characteristics of included studies that investigated non-biomedical factors influencing outpatient and community antibiotic use in China

\begin{tabular}{|c|c|c|}
\hline Characteristic & $\begin{array}{l}\text { Number of } \\
\text { studies }\end{array}$ & Studies \\
\hline Total & 54 & $13-36$ 38-63 73-76 \\
\hline \multicolumn{3}{|l|}{ Language } \\
\hline Chinese & 11 & 2933354142444649626376 \\
\hline English & 43 & 13-28 30-32 34 36 38-40 43454748 50-61 73-75 \\
\hline \multicolumn{3}{|l|}{ Year of study } \\
\hline 2001-2005 & 2 & 2639 \\
\hline $2006-2010$ & 3 & 153358 \\
\hline 2011-2015 & 19 & $161821232429-3234$ 40-44 47495773 \\
\hline 2016-later & 30 & 131417192022252728353638454648 50-56 59-63 74-76 \\
\hline \multicolumn{3}{|l|}{ Study design } \\
\hline Quantitative study & 44 & $13-15$ 17-26 28-30 33-36 38-55 6263 73-76 \\
\hline Longitudinal & 1 & $\mathrm{x}$ \\
\hline Cross-sectional & 38 & $13-15$ 17-22 26 28-30 33-36 38-52 $626373-76$ \\
\hline Experiment & 6 & $23-2553-55$ \\
\hline Qualitative study & 5 & $2757-5961$ \\
\hline Mixed-methods & 5 & 1631325660 \\
\hline Experiment & 1 & 56 \\
\hline \multicolumn{3}{|l|}{ Study region } \\
\hline \multicolumn{3}{|l|}{ Mainland China } \\
\hline East & 14 & $2324343540-4246484952606263$ \\
\hline Central & 7 & 14182747617576 \\
\hline West & 6 & 222943445859 \\
\hline Across regions & 17 & $131719202528363845505153-5774$ \\
\hline Hong Kong & 9 & $1516212630-323973$ \\
\hline Taiwan & 1 & 33 \\
\hline \multicolumn{3}{|l|}{ Urbanicity } \\
\hline Urban & 10 & 28333441425561627376 \\
\hline Rural & 7 & 14252752575960 \\
\hline Both & 33 & $1315-242629-323536383943-47$ 49-51 5354565863 \\
\hline Unknown & 4 & 40487475 \\
\hline \multicolumn{3}{|l|}{ Participants } \\
\hline \multicolumn{3}{|l|}{ Healthcare consumers } \\
\hline $\begin{array}{l}\text { General public } \\
\text { (adults >18years) }\end{array}$ & 29 & 14-17 19-21 29-36 $3840434446-505257626373$ \\
\hline Parents or caregivers & 8 & 1318284142455176 \\
\hline \multicolumn{3}{|l|}{ Healthcare providers } \\
\hline $\begin{array}{l}\text { Healthcare professionals and/or } \\
\text { community pharmacies }\end{array}$ & 13 & 22-26 39 53-55606174 75 \\
\hline Both sides of healthcare system & 4 & 27565859 \\
\hline \multicolumn{3}{|l|}{ Antibiotic misuse in the community } \\
\hline Self-medication with antibiotics & 34 & $13-2127-3640-4648-52586263$ \\
\hline Taking antibiotics as prophylaxis & 12 & $1317-2036384350-5257$ \\
\hline Over-the-counter purchases/sales & 22 & $151618212830-334144485052-5976$ \\
\hline Patient side reported & 19 & 1516182128 30-33 $414448505256-5976$ \\
\hline
\end{tabular}




\begin{tabular}{cll}
\hline & Number of & \\
Characteristic & studies & Studies \\
\hline Experiment & 4 & $53-56$ \\
Household storage of antibiotics & 23 & $131416-21282931323541-434650-52586263$ \\
\hline Demand for antibiotic prescriptions & 23 & 13 16-21 27-36 38 47 57 62 63 76 \\
\hline
\end{tabular}

$23.7 \%^{15}$ to $63.0 \%{ }^{16}$ in Hong Kong. Three studies found that $31.7 \%$ to about $50 \%^{18}$ of participants prescribed with antibiotics were administered them through intravenous infusion. ${ }^{17-19}$ Six studies investigated how patients' socioeconomic backgrounds might influence antibiotic prescribing $^{13} 1417$ 20-22 and among them, two identified patients' antibiotics-related knowledge as a determinant. ${ }^{1417}$ People with a medical background were less likely to receive antibiotic prescriptions and more likely to approve of that decision..$^{20}$ Regional differences were also noted: living in regions of lower economic development was associated with an increased risk of antibiotic prescriptions for selflimiting illnesses. ${ }^{1320}$ Three experiments using SPM were conducted in the past decade to investigate drivers of antibiotic misuse by providers and concluded that antibiotic dispensing practices in mainland China have been mainly influenced by financial incentives for prescriers and/or dispensing facilities, ${ }^{23}{ }^{24}$ lack of diagnostic capacity ${ }^{25}$ and concerns over complications. ${ }^{25-27}$

\section{Demand for antibiotic prescriptions}

Demand for antibiotic prescriptions from patients and/or caregivers was reported in 21 studies, ranging from $1.8 \%^{28}$ to $74.5 \%{ }^{29}$ in mainland China, compared with around 8.7\% ${ }^{162130-32}$ and $8.8 \%{ }^{33}$ in Hong Kong and Taiwan, respectively. Out of the 21 studies, 9 identified factors influencing demands for antibiotic prescriptions. 131719202930 34-36 Two found knowledge to be a protective factor associated with demands for antibiotics. ${ }^{1736}$ Having some level of medical education was found to have mixed effects. ${ }^{20} 37$ Older age, ${ }^{131920}$ lower education levels ${ }^{1329}$ and living in rural $\operatorname{areas}^{29}$ or regions with lower economic development ${ }^{20}$ were associated with an increased risk of inappropriate prescriptions by demand among patients and caregivers. People became less likely to demand antibiotic prescriptions after living in a region with better drug regulations. ${ }^{38}$ Two Hong Kong-based studies examined the reasons family doctors prescribed antibiotics for upper respiratory tract infections (URTI), and found reasons for this included 'no energy to resist demand', ${ }^{26}$ 'lack of time ${ }^{, 26}{ }^{39}$ and 'as a way to terminate the consultation'. ${ }^{39}$ They also found male doctors in Hong Kong to be more likely to over-prescribe antibiotics than their female peers. ${ }^{26} 39$

\section{Community settings}

\section{Self-medication with antibiotics for treatment}

The practice of self-medication with antibiotics for treatment was widely reported in 32 studies, all in mainland China. The overall prevalence of antibiotic self-medication (for therapeutic purposes) ranged from $7.6 \%^{14}$ to $82.6 \%{ }^{29}$ in mainland China, with high prevalence found in Gansu (82.6\%), ${ }^{29}$ Guangdong $(63.5 \%$ in Guangzhou City) ${ }^{40-42}$ Shaanxi (60.6\% in Xi'an City) ${ }^{284344}$ and Jiangxi $(62 \%) .{ }^{18}$ Out of 32 studies, 5 assessed the impact of knowledge on antibiotic self-medication with mixed results. ${ }^{1728} 364546$ Having an accepting attitude towards antibiotic self-medication ${ }^{28}$ and perceived susceptibility and perceived severity of the infection ${ }^{28} 47$ were associated with increased odds of antibiotic selfmedication. Older age, ${ }^{18} 404548$ being women ${ }^{28} 4849$ and having more than one child in the house ${ }^{18}$ were associated with higher rates of antibiotic self-medication. The associations between antibiotic self-medication and education and urbanicity were inconsistent: some studies identified having higher education ${ }^{18}{ }^{29}$ or living in the urban areas ${ }^{43} 4449$ to be risk factors, while others came to the opposite conclusion. ${ }^{18} 2829424549-51$ Having some level of medical education was associated with a higher likelihood of antibiotic self-medication compared with peers. ${ }^{20} 283440414344484951$

\section{Self-medication with antibiotics for prophylaxis}

Patterns were similar for associations withself-medication with antibiotics as prophylaxis-often for URTI to prevent deterioration-measured in 11 studies, ${ }^{13}$ 17-20 363843 50-52 all in mainland China, with a prevalenceranging from $10.3 \% 19$ to $30.6 \%{ }^{43}$ Notably, regional differences were observedfor antibiotic self-medication, both for therapeutic purposes and prophylaxis:consistently, those living in highly economically developed regions were lesslikely to self-medicate with antibiotics, compared with their counterparts. ${ }^{13} 20285051$ Having health insurance was also associated with higher rates of antibiotic self-medication. ${ }^{28}$ Having the idea that antibiotics could preventhumans with a common cold from developing into more severe diseases wasassociated with backyard pig farmers adding antibiotics into pig feed. ${ }^{52}$

\section{Over-the-counter (OTC) purchases of antibiotics}

Access to non-prescription antibiotics, either via over-thecounter purchases or household storage, was strongly associated with antibiotic self-medication for therapeutic purposes $^{1718284142465051}$ or prophylaxis. ${ }^{5051}$ The prevalence of over-the-counter (OTC) purchases of antibiotics ranged from $8.8 \%^{14}$ to $84.9 \%{ }^{52}$ in mainland China, $7.3 \%^{1531}$ to $7.8 \%{ }^{16213032}$ in Hong Kong and was around $10.0 \%^{33}$ in Taiwan. Antibiotics were easily obtainable 
Table 2 Non-biomedical factors influencing outpatient and community antibiotic use for common community-acquired infections

\begin{tabular}{|c|c|c|c|}
\hline \multirow[b]{2}{*}{ Non-biomedical factors } & \multirow[b]{2}{*}{ Application/examples } & \multicolumn{2}{|l|}{$\begin{array}{l}\text { Inappropriate antibiotic use } \\
\text { (including prevention use) }\end{array}$} \\
\hline & & Antibiotic use behaviour outcomes & References \\
\hline \multicolumn{4}{|l|}{ Knowledge } \\
\hline $\begin{array}{l}\text { General knowledge about } \\
\text { antibiotics/AMR }\end{array}$ & $\begin{array}{l}\text { Combined knowledge score } \\
\text { Inadequate diagnostic knowledge of } \\
\text { doctors } \\
\text { Misconceptions (eg, antibiotic is an } \\
\text { anti-inflammatory drug) }\end{array}$ & $\begin{array}{l}\text { Asking/pressuring doctors for } \\
\text { antibiotics } \\
\text { Self-medication with antibiotics } \\
\text { Storing antibiotics at home } \\
\text { Taking antibiotics as prophylaxis } \\
\text { Healthcare seeking behaviour } \\
\text { The likelihood to be prescribed with } \\
\text { antibiotics by doctors } \\
\text { Combined behaviour score }\end{array}$ & 141725364663 \\
\hline Literacy & $\begin{array}{l}\text { Being able to recognise antibiotics } \\
\text { Knowing when/how to use antibiotics }\end{array}$ & No evidence available to date & - \\
\hline $\begin{array}{l}\text { Knowledge about the } \\
\text { infection }\end{array}$ & $\begin{array}{l}\text { The participant's knowledge about the } \\
\text { specific infection (eg, URTI symptoms } \\
\text { will dissipate naturally) }\end{array}$ & No evidence available to date & - \\
\hline AMR awareness & $\begin{array}{l}\text { The participant's awareness of AMR as } \\
\text { a health threat on individual or on the } \\
\text { society as a whole }\end{array}$ & No evidence available to date & - \\
\hline
\end{tabular}

\section{Attitudes}

\begin{tabular}{|c|c|c|c|}
\hline $\begin{array}{l}\text { Attitudes towards } \\
\text { antibiotic misuse } \\
\text { behaviours }\end{array}$ & $\begin{array}{l}\text { The participant's accepting attitudes } \\
\text { towards storing/self-medicating with } \\
\text { antibiotics }\end{array}$ & $\begin{array}{l}\text { Self-medication with antibiotics } \\
\text { Storing antibiotics at home }\end{array}$ & 2852 \\
\hline Self-efficacy & $\begin{array}{l}\text { The participant's perception of his/her } \\
\text { or others' competence in engaging in } \\
\text { caring for the infection or in antibiotic } \\
\text { use }\end{array}$ & No evidence available to date & - \\
\hline Medical background & $\begin{array}{l}\text { The participants or their family } \\
\text { members having some level of medical } \\
\text { education }\end{array}$ & $\begin{array}{l}\text { Asking/pressuring doctors for } \\
\text { antibiotics } \\
\text { Self-medication with antibiotics } \\
\text { Over-the-counter purchases } \\
\text { Storing antibiotics at home } \\
\text { Taking antibiotics as prophylaxis } \\
\text { The likelihood to be prescribed with } \\
\text { antibiotics by doctors } \\
\text { Combined behaviour score }\end{array}$ & $13192028344041434447-51$ \\
\hline Perceived susceptibility & Self-rated health status & $\begin{array}{l}\text { Self-medication with antibiotics } \\
\text { Combined behaviour score }\end{array}$ & 284663 \\
\hline Perceived severity & $\begin{array}{l}\text { The participant's assessment/ } \\
\text { perception of the severity of the } \\
\text { situation regarding the infection (eg, } \\
\text { self-diagnosed symptoms experienced) } \\
\text { The participant's perception of } \\
\text { potential harm of over-the-counter } \\
\text { purchase }\end{array}$ & Over-the-counter purchase & 32 \\
\hline $\begin{array}{l}\text { Perceived benefits and } \\
\text { disbenefits }\end{array}$ & $\begin{array}{l}\text { The participant's mistaken } \\
\text { understanding of antibiotics } \\
\text { (eg, considering antibiotics as } \\
\text { Xiaoyanyao, anti-inflammatory drugs) } \\
\text { (misconceptions) }\end{array}$ & $\begin{array}{l}\text { Asking/pressuring doctors for } \\
\text { antibiotics } \\
\text { Self-medication with antibiotics } \\
\text { Taking antibiotics as prophylaxis }\end{array}$ & 36 \\
\hline
\end{tabular}


Table 2 Continued

Inappropriate antibiotic use

(including prevention use)

\begin{tabular}{|c|c|c|c|}
\hline \multirow[b]{2}{*}{ Non-biomedical factors } & \multirow[b]{2}{*}{ Application/examples } & & \\
\hline & & Antibiotic use behaviour outcomes & References \\
\hline Perceived barriers & $\begin{array}{l}\text { The participant's assessment/ } \\
\text { perception of barriers to engaging in } \\
\text { antibiotic use (health insurance and } \\
\text { knowledge of current policy) }\end{array}$ & $\begin{array}{l}\text { Self-medication with antibiotics } \\
\text { Healthcare seeking behaviour }\end{array}$ & 1428 \\
\hline Family dynamics & $\begin{array}{l}\text { Family members who might influence } \\
\text { the healthcare decisions of caregiver or } \\
\text { the patients }\end{array}$ & Self-medication with antibiotics & 2845 \\
\hline Access to antibiotics & $\begin{array}{l}\text { Access to antibiotics, with or without } \\
\text { prescription }\end{array}$ & & \\
\hline $\begin{array}{l}\text { Access to non- } \\
\text { prescription antibiotics }\end{array}$ & $\begin{array}{l}\text { Over-the-counter purchase } \\
\text { Antibiotics stored at home } \\
\text { Leftover prescriptions }\end{array}$ & $\begin{array}{l}\text { Self-medication with antibiotics } \\
\text { Taking antibiotics as prophylaxis }\end{array}$ & 171828314142465051 \\
\hline Cues to action & $\begin{array}{l}\text { External trigger mechanisms to prompt } \\
\text { engagement in antibiotic use behaviour }\end{array}$ & & \\
\hline Symptoms & Presence of fever & No evidence available to date & - \\
\hline $\begin{array}{l}\text { Information sources and } \\
\text { seeking for therapeutic } \\
\text { purposes decisions }\end{array}$ & $\begin{array}{l}\text { Expectation for antibiotic use } \\
\text { knowledge }\end{array}$ & Combined behaviour score & 63 \\
\hline
\end{tabular}

\section{Socio-contextual factors}

\begin{tabular}{|c|c|c|c|}
\hline Age & The age of the participant or caregiver & $\begin{array}{l}\text { Asking/pressuring doctors for } \\
\text { antibiotics } \\
\text { Self-medication with antibiotics } \\
\text { Over-the-counter purchase } \\
\text { Storing antibiotics at home } \\
\text { Taking antibiotics as prophylaxis } \\
\text { Healthcare seeking behaviour } \\
\text { The likelihood to be prescribed } \\
\text { with antibiotics by doctors (oral, } \\
\text { intravenous or both) } \\
\text { Combined behaviour score }\end{array}$ & $131418-20324041454748505176$ \\
\hline Gender & $\begin{array}{l}\text { The gender of the participant or } \\
\text { caregiver }\end{array}$ & $\begin{array}{l}\text { Self-medication with antibiotics } \\
\text { Storing antibiotics at home } \\
\text { Taking antibiotics as prophylaxis } \\
\text { Healthcare seeking behaviour } \\
\text { Combined behaviour score }\end{array}$ & 13-15 $192028354548-51$ \\
\hline Education & $\begin{array}{l}\text { The education level of the participant, } \\
\text { his/her parent or the caregiver }\end{array}$ & $\begin{array}{l}\text { Asking/pressuring doctors for } \\
\text { antibiotics } \\
\text { Self-medication with antibiotics } \\
\text { Storing antibiotics at home } \\
\text { Over-the-counter purchases } \\
\text { Taking antibiotics as prophylaxis } \\
\text { Healthcare seeking behaviour } \\
\text { Combined behaviour score }\end{array}$ & $131418-20282938424549-516376$ \\
\hline Income & $\begin{array}{l}\text { The household income or monthly } \\
\text { allowance of the participant or } \\
\text { caregiver }\end{array}$ & $\begin{array}{l}\text { Self-medication with antibiotics } \\
\text { Storing antibiotics at home } \\
\text { Taking antibiotics as prophylaxis }\end{array}$ & 20293240455051 \\
\hline
\end{tabular}

Continued 
Table 2 Continued

Inappropriate antibiotic use

(including prevention use)

\begin{tabular}{ll} 
Non-biomedical factors & A \\
\hline Location & T \\
& \\
&
\end{tabular}

Region

Region of residence of the participant or caregiver-geographic area or economic development stage

\section{Application/examples}

The rural/urban of residence of the participant or caregiver

Antibiotic use behaviour outcomes References

Asking/pressuring doctors for

13 18-20 2429 43-45 47 49 50 antibiotics

Self-medication with antibiotics

Over-the-counter purchases

Storing antibiotics at home

Taking antibiotics as prophylaxis

The likelihood to be prescribed with

antibiotics by doctors

Combined behaviour score

Asking/pressuring doctors for 1320285051 antibiotics

Self-medication with antibiotics

Over-the-counter purchases

Storing antibiotics at home

Taking antibiotics as prophylaxis

The likelihood to be prescribed with

antibiotics by doctors

\begin{tabular}{|c|c|c|c|}
\hline Policy & $\begin{array}{l}\text { Health policy or AMR programme that } \\
\text { might affect prescribing or access } \\
\text { to antibiotics (eg, measures to de- } \\
\text { incentivise over-prescription in public } \\
\text { health facilities, including decoupling } \\
\text { the link between facility income and the } \\
\text { sale of medicines and policy that bans } \\
\text { over-the-counter purchases) } \\
\text { Financial incentives for antibiotic } \\
\text { prescribing of doctors }\end{array}$ & $\begin{array}{l}\text { Self-medication with antibiotics } \\
\text { Over-the-counter purchases* } \\
\text { The likelihood to be prescribed with } \\
\text { antibiotics by doctors }\end{array}$ & 232428 \\
\hline Norm & $\begin{array}{l}\text { Participants' view of how others treat } \\
\text { illnesses and/or use antibiotics (non- } \\
\text { China and non-predictor) } \\
\text { Healthcare providers reviewing others' } \\
\text { prescriptions (non-predictor)* }\end{array}$ & $\begin{array}{l}\text { The likelihood to be prescribed with } \\
\text { antibiotics by doctors* }\end{array}$ & $597577-79$ \\
\hline Point-of-care & $\begin{array}{l}\text { Prescribing habits/capacity might vary } \\
\text { at different levels of health facilities: } \\
\text { tertiary hospital, secondary/county } \\
\text { hospital, community health centres/ } \\
\text { township hospital or private clinics/ } \\
\text { village clinics }\end{array}$ & No evidence available to date & - \\
\hline
\end{tabular}

${ }^{*}$ Non-predictor: effect is implied.

AMR, antimicrobial resistance; URTI, upper respiratory tract infections.

with very limited barriers from $48.5 \%^{53}$ to $83.6 \%^{54}$ of local pharmacies across mainland China when an acute diarrhoea or URTI was present in four experiments using SCM. ${ }^{53-56}$ The geographic location of the pharmacy, ${ }^{53-55}$ the distance from a hospital, ${ }^{54}$ being a chain pharmacy, ${ }^{53}$ having a special counter for antibiotic ${ }^{54}$ and having a licensed pharmacist on duty ${ }^{53-55}$ were all associated with OTC antibiotic dispensing. Backyard pig farmers who had purchased antibiotics for their pigs over the counter in the previous year were more likely to do so for humans. ${ }^{52}$

\section{Household storage of antibiotics}

The prevalence of household storage of antibiotics ranged from $25.3 \%^{28}$ to $80.2 \%{ }^{42}$ in mainland China and was around $6 \%$ in Hong Kong, ${ }_{16} 213132$ principally originating from over-the-counter purchases ${ }^{174} 5051$ and leftover prescriptions. ${ }^{161731415051}$ Being women, ${ }^{13} 19205051$ of older age, ${ }^{13} 5051$ attaining higher education, ${ }^{13} 19205051$ having higher income ${ }^{205051}$ and living in urban areas ${ }^{192050}$ were associated with a higher likelihood of household storage of antibiotics. For backyard pig farmers, perceiving it good to store antibiotics at home was associated with higher risks for keeping antibiotics at home for both pigs and humans. ${ }^{52}$ Unsurprisingly, over-the-counter purchases ${ }^{31}$ were a risk factor for storing antibiotics at home.

\section{Qualitative studies}

Factors of antibiotic use identified from nine qualitative and mixed methods studies ${ }^{16} 2731324856-59$ generally supported the quantitative findings. Participants' trust in their doctors ${ }^{31}$ made them not demand antibiotics; on the other hand, previous 'successful' experiences with 


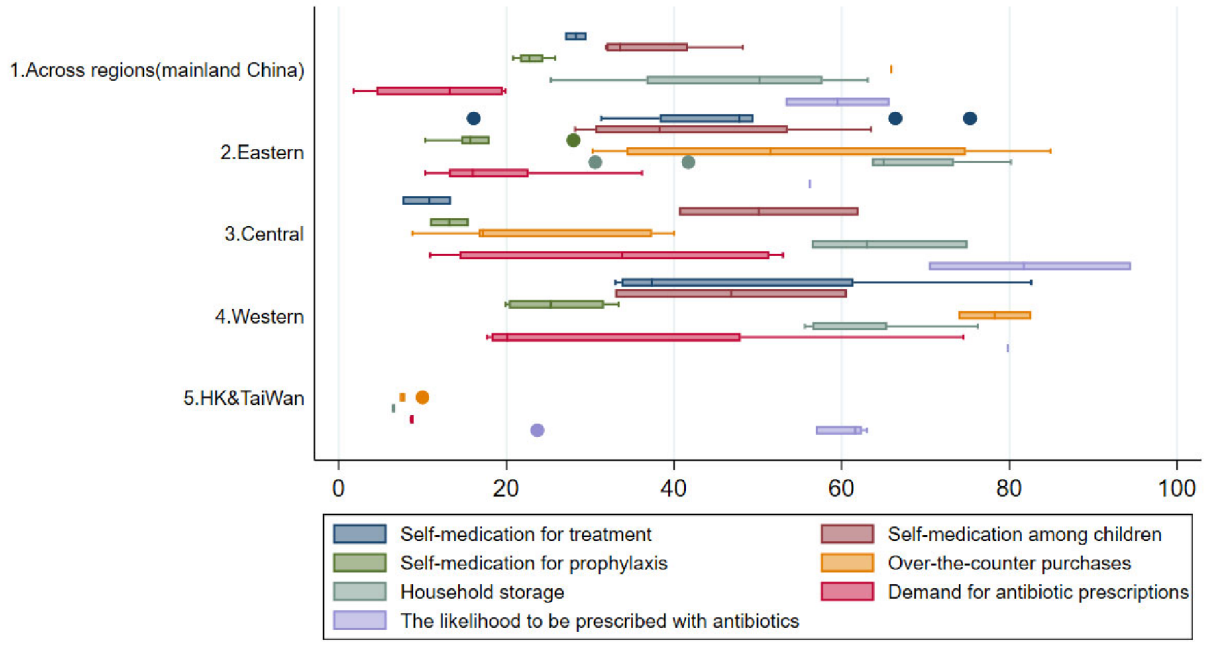

Figure 2 Synthesis of quantitative data on public antibiotic misuse behaviours in the community by study region.

similar symptoms prompted them to ask for antibiotics. ${ }^{57}$ Rural residents viewed self-medication, over-the-counter purchases for self-limiting conditions such as diarrhoea and colds, and storing antibiotics at home for future use, as norms. ${ }^{58}$ Inappropriate antibiotic dispensing was reported as a severe issue in less economically developed regions like Guizhou, where antibiotics became a routine prescription for patients suffering from any symptom other than fatigue, due to strong financial incentives for over-prescribing. ${ }^{58}$ From the prescribers' perspective, lack of diagnostic capacity, such as inability to perform a routine blood test and a $\mathrm{C}$ reactive test, and fears of complications, such as pneumonia, bronchitis and otitis media, were the most frequently reported reasons for antibiotic prescriptions. ${ }^{27}$ Pressure to maintain a good doctor-patient relationship to maintain business was also reported as a reason to fulfil patients' requests for antibiotic prescriptions. ${ }^{27} 59$ One study found clinical trainings to be effective in improving doctors' knowledge and antibiotic prescribing behaviours. ${ }^{59}$ The overall context of pervasive non-prescription antibiotic dispensing in China can be attributed to the financial incentives from selling antibiotics and associated traditional Chinese medicines, inadequate Food and Drug Administration (FDA) supervision and lack of forceful regulations also prompted pharmacies to continue this practice for consumer retention. $^{56}$

\section{Antibiotic use practices specific to the Chinese context}

Among the 54 included studies, 11 studies $^{16-18} 22 \quad 28313536435759$ found a misconception existed confusing anti-inflammatory medications and antibiotics, ranging in prevalence from $17.9 \%^{17}$ to $71.6 \%,{ }^{28}$ even with $30.1 \%$ in paediatricians. ${ }^{22}$ Eleven studies ${ }^{1417182728313540434657}$ reported a preference for intravenous injection of antibiotics, where $21.3 \%{ }^{17}$ $84.7 \%{ }^{46}$ of participants believed infusion is much more efficacious than oral administration, and even $74 \%$ doctors thought the same way. ${ }^{60}$ In a less economically developed region like Guizhou, intravenous antibiotic treatment was common for mild diarrhoea, often in the absence of a proper diagnostic test. ${ }^{58}$ Mixing antibiotics with traditional Chinese medicine or preferences for traditional Chinese medicine over antibiotics for relieving cold symptoms were observed. ${ }^{21}{ }^{58}$ One found users of traditional Chinese medicine were less likely to accept antibiotics when offered $(\mathrm{OR}=0.38,95 \% \mathrm{CI}$ 0.25 to 0.60 ) and were less likely to be treated with antibiotics for their last URTI $(\mathrm{OR}=0.49,95 \%$ CI 0.27 to 0.81$).{ }^{21}$ Others found doctors prescribed antibiotics for URTI and combined antibiotic prescriptions with traditional Chinese medicine to relieve symptoms. ${ }^{21} 58$ Self-medication is common in the Chinese community; doctors reported their patients had self-medicated with antibiotics before reaching health facilities. ${ }^{27} 61$ Antibiotics were also widely used in animals by farmers without professional supervision. ${ }^{52}$

The results of quality appraisal of the 54 studies were reported in online supplemental files S4-S6. Adapted from Health Belief Model, figure 3 presented a conceptual framework ${ }^{9}$ of non-biomedical factors that influence outpatient and community antibiotic use for common community-acquired infections.

\section{DISCUSSION}

\section{Summary of findings}

In this systematic review, quantitative synthesis showed that inappropriate antibiotic use is pervasive throughout mainland China, given the relatively easy access to antibiotics, with or without a prescription. Access to nonprescription antibiotics, either via over-the-counter purchases or household storage, was strongly associated with antibiotic self-medication. ${ }^{17} 18284142465051$ Public AMR awareness levels were frequently measured to be high in mainland China ${ }^{15-19} 212830313435404346-4862$ 63; however, there is little evidence that high awareness in China could lead to better antibiotic use. Striking regional 


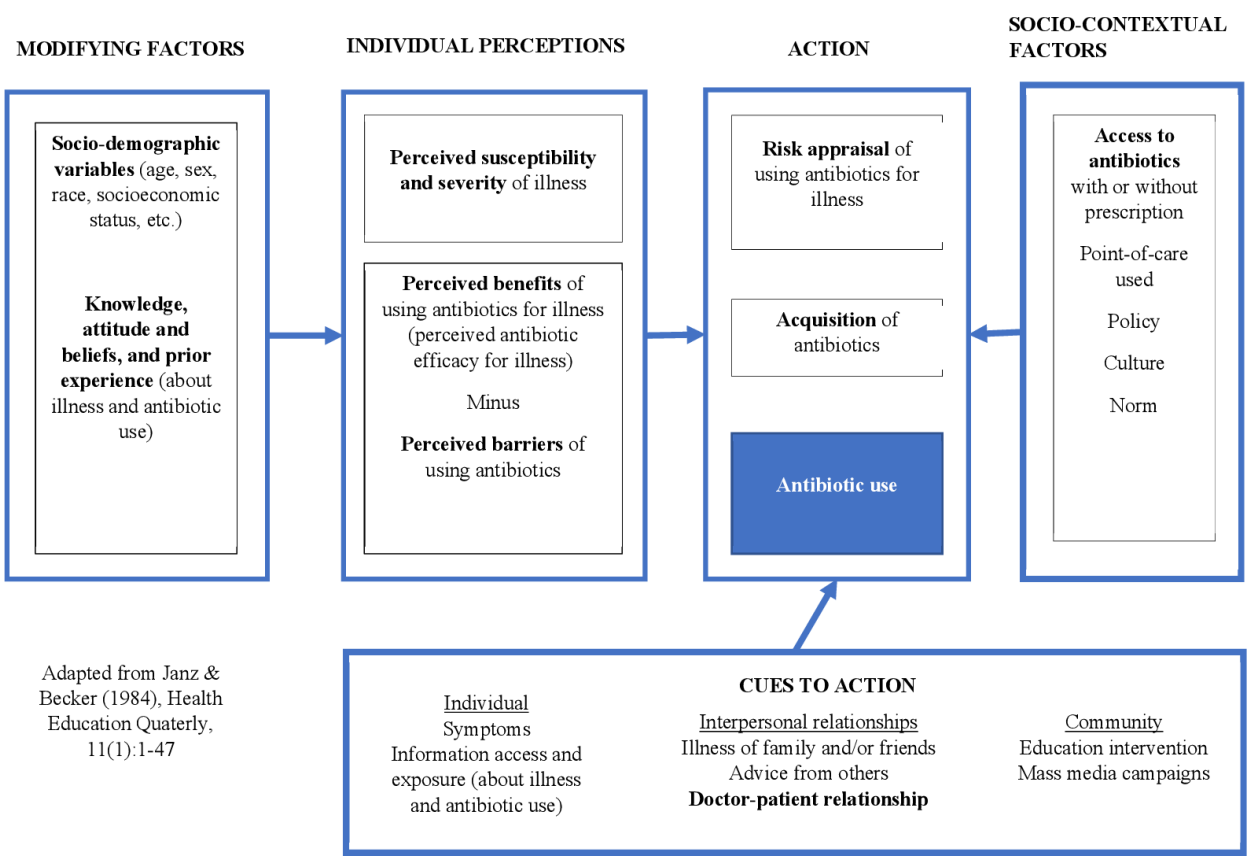

Figure 3 Modified health belief model for public antibiotic use.

differences were observed for antibiotic self-medication; those living in less economically developed regions were more likely to use antibiotics inappropriately. ${ }^{132} 285051$ Having the experiences of OTC purchases for pig use was associated with a higher risk of obtaining antibiotics over the counter for human use in backyard pig farmers. ${ }^{52}$ Both quantitative and qualitative studies in this review revealed that doctor-patient relationships are critical in influencing unnecessary or inappropriate antibiotic prescriptions. Patients who trust their doctors, as well as people with some medical education or a higher education level would likely accept non-antibiotic prescriptions. ${ }^{202931}$ Financial incentives for doctors led to inappropriate over-prescription of antibiotics. ${ }^{23}{ }^{24}$ Nonprescription antibiotic sales were prevalent in community pharmacies. ${ }^{53-56}$ Antibiotic use is influenced by the local context in mainland China, where a misconception confusing anti-inflammatory medications and antibiotics, ${ }^{16-18} 283135364357$ and a preference for intravenous injection of antibiotics 1417182728313540434657 are prevalent.

\section{Strengths and limitations of the review}

To the best of our knowledge, this is the first mixedmethods systematic review of the prevalence, measures and factors of antibiotic use across China. This comprehensive review included studies across different regions of mainland China, Hong Kong and Taiwan, published in English and Chinese. It captured statistically assessed factors of actual antibiotic use behaviours by both healthcare providers and consumers, rather than only considering their knowledge, attitudes or intentions in isolation of these influencing factors. We further synthesised the findings using the Health Belief Model, which could identify a critical knowledge gap with a lack of evidence on several key factors on antibiotic use practice (see table 2) and inform the development of future behavioural change interventions to reduce antibiotic use in the community. The data and study design presented in the Chinese language publications were lean in general and therefore, for our review, we limited the inclusion to studies that had demonstrated sufficient rigour and detail in their reporting for us to appraise their evidence.

\section{Interpretation}

Inappropriate use of antibiotics is influenced by nonbiomedical factors within and beyond clinical settings that are unique to mainland China, yet common among lowincome and middle-income countries, including public misconceptions, ${ }^{16-1822} 28313536435759$ habitual use without professional guidance, ${ }^{58}$ insufficient FDA monitoring, ${ }^{56}$ incentivising the healthcare system towards prescribing and selling, ${ }^{23} 2456$ lack of diagnostic capacity ${ }^{25} 27$ and the delicate relationships between patients and prescribers, ${ }^{27}$ but some critical factors such as antibiotic literacy remained as research gaps. To date, there have been only few interventions implemented in primary care settings to reduce inappropriate prescribing, ${ }^{64-70}$ largely targeting clinicians and ignoring demand-side factors. Further, more research is needed to investigate the associations between human and animal use of antibiotics in rural China, where 564 million people reside ${ }^{71}$ in order to inform effective One Health interventions.

This study found an urgent need to take an evidencebased approach to identify determinants of antibiotic use practices within the target context, programme parameters for improvement and intervention components to optimise the use of antibiotics. These insights will be critical to tailor contextualised, multifaceted interventions for reducing inappropriate antibiotic use. For example, 
despite the AMR awareness campaigns invested in by the Chinese government, the inappropriate use of antibiotics was found to be prevalent across the country. Moreover, a study reported that well-intentioned government publicity about antibiotic abuse may have had the unintended consequence of increasing antibiotic prescriptions and exacerbating resistance. ${ }^{58}$ Such a phenomenon might be explained by the non-rational strategies people lean on while managing the type of risk and uncertainty associated with an acute infection: so-called tacit or experiential knowledge such as trust, intuition, emotion and prior 'successful' experiences with similar symptoms for healthcare decision making. ${ }^{572}$ Also, we found the national ban on over-the-counter purchases of antibiotics has been very limited in its impact-non-prescription purchases and use of antibiotics were reported across mainland China. Furthermore, few studies investigated the common practice-very much influenced by local context-in which physicians and pharmacists prepare cocktails of various medications, including traditional Chinese medicine and antibiotic agents for patients with URTI. ${ }^{21} 5658$ Inappropriate antibiotic consumption is unlikely to decrease without multifaceted, contexttailored strategies targeting patients, prescribers and healthcare systems.

\section{CONCLUSION}

This review revealed the impact of non-biomedical factors at individual, community, health system and societal levels on outpatient and community antibiotic use by healthcare users and providers in the Chinese context and demonstrated that they impact each other in an interactive manner. Given the large population size and consumption volume, the threat to human health from the adverse side effects of inappropriate use and drug resistance calls for immediate action. This study calls for multifaceted antibiotic stewardship programmes and strictive antibiotic drug policy, with a One Health framework. Future AMR strategies should incorporate an evidence-based, context-tailored design that simultaneously addresses drivers of antibiotic misuse from both the supply-side and demand-side within and beyond clinical settings.

Contributors LL: conceptualisation, methodology, writing-original draft preparation and editing; RS: data curation and coding, visualisation and writingoriginal draft preparation; TY: data curation and coding, visualisation and writingoriginal draft preparation; XZ: supervision; $\mathrm{SH}$ : supervision and writing- reviewing and editing.

Funding This study is supported by the Wellcome Trust [Grant no. 215373/Z/19/Z]. Competing interests None declared.

Patient consent for publication Not required.

Provenance and peer review Not commissioned; externally peer reviewed.

Data availability statement All data relevant to the study are included in the article or uploaded as supplementary information.

Supplemental material This content has been supplied by the author(s). It has not been vetted by BMJ Publishing Group Limited (BMJ) and may not have been peer-reviewed. Any opinions or recommendations discussed are solely those of the author(s) and are not endorsed by BMJ. BMJ disclaims all liability and responsibility arising from any reliance placed on the content. Where the content includes any translated material, BMJ does not warrant the accuracy and reliability of the translations (including but not limited to local regulations, clinical guidelines, terminology, drug names and drug dosages), and is not responsible for any error and/or omissions arising from translation and adaptation or otherwise.

Open access This is an open access article distributed in accordance with the Creative Commons Attribution 4.0 Unported (CC BY 4.0) license, which permits others to copy, redistribute, remix, transform and build upon this work for any purpose, provided the original work is properly cited, a link to the licence is given, and indication of whether changes were made. See: https://creativecommons.org/ licenses/by/4.0\%.

\section{ORCID iD}

Leesa Lin http://orcid.org/0000-0003-4123-4762

\section{REFERENCES}

1 WHO. World Health organization. antimicrobial resistance: global report on surveillance, 2014. Available: https://www.who.int/ drugresistance/documents/surveillancereport/en/ [Accessed last accessed: May 2019].

2 Costelloe C, Metcalfe C, Lovering A, et al. Effect of antibiotic prescribing in primary care on antimicrobial resistance in individual patients: systematic review and meta-analysis. BMJ 2010;340:c2096.

3 Goossens H, Ferech M, Vander Stichele R, et al. Outpatient antibiotic use in Europe and association with resistance: a crossnational database study. Lancet 2005;365:579-87.

4 Tang Q, Song P, Li J, et al. Control of antibiotic resistance in China must not be delayed: the current state of resistance and policy suggestions for the government, medical facilities, and patients. Biosci Trends 2016;10:1-6.

$5 \mathrm{Li} \mathrm{J}$, Song X, Yang T, et al. A systematic review of antibiotic prescription associated with upper respiratory tract infections in China. Medicine 2016;95:e3587.

6 Wang J, Wang P, Wang X, et al. Use and prescription of antibiotics in primary health care settings in China. JAMA Intern Med 2014;174:1914-20.

7 Ancillotti M, Eriksson S, Veldwijk J, et al. Public awareness and individual responsibility needed for judicious use of antibiotics: a qualitative study of public beliefs and perceptions. BMC Public Health 2018;18:1153.

8 Weissman J, Besser RE. Promoting appropriate antibiotic use for pediatric patients: a social ecological framework. Semin Pediatr Infect Dis 2004:15:41-51.

9 Lin L, Fearon E, Harbarth S, et al. Decisions to use antibiotics for upper respiratory tract infections across China: a large-scale cross-sectional survey among university students. BMJ Open 2020;10:e039332.

$10 \mathrm{Bmj}$ critical appraisal checklist for a questionnaire study. Available: https://www.bmj.com/content/suppl/2004/05/27/328.7451.1312. DC1

11 The critical appraisals skills programme (CASP) appraisal checklists. Available: https://casp-uk.net/casp-tools-checklists/

12 Hong QN, Pluye P, bregues S F, et al. Mixed methods appraisal tool (MMAT), version 2018. Registration of copyright 2018;1148552.

$13 \mathrm{Xu}$ Y, Lu J, Sun C, et al. A cross-sectional study of antibiotic misuse among Chinese children in developed and less developed provinces. $J$ Infect Dev Ctries 2020;14:129-37.

14 Chai J, Coope C, Cheng J, et al. Cross-Sectional study of the use of antimicrobials following common infections by rural residents in Anhui, China. BMJ Open 2019;9:e024856.

15 You JHS, Yau B, Choi KC, et al. Public knowledge, attitudes and behavior on antibiotic use: a telephone survey in Hong Kong. Infection 2008:36:153-7.

16 Lam TP, Lam KF, Ho PL, et al. Knowledge, attitude, and behaviour toward antibiotics among Hong Kong people: local-born versus immigrants. Hong Kong Med J 2015;21 Suppl 7:S41-7.

17 Wang X, Peng D, Wang W, et al. Massive misuse of antibiotics by university students in all regions of China: implications for national policy. Int $J$ Antimicrob Agents 2017;50:441-6.

18 Yu M, Zhao G, Stålsby Lundborg C, et al. Knowledge, attitudes, and practices of parents in rural China on the use of antibiotics in children: a cross-sectional study. BMC Infect Dis 2014;14:112.

19 Hu Y, Wang X, Tucker J, et al. Knowledge, attitude, and practice with respect to antibiotic use among Chinese medical students: a 
multicentre cross-sectional study. Int J Environ Res Public Health 2018;15:1165

20 Peng D, Wang X, Xu Y, et al. Antibiotic misuse among university students in developed and less developed regions of China: a crosssectional survey. Glob Health Action 2018;11:1496973.

21 Wun YT, Lam TP, Lam KF, et al. Comparison of the knowledge, attitudes and practice with antibiotic use between traditional Chinese medicine and Western medicine usual attenders in Hong Kong. Complement Ther Med 2014;22:99-106.

22 Ye D, Yan K, Zhang H, et al. A survey of knowledge, attitudes and practices concerning antibiotic prescription for upper respiratory tract infections among pediatricians in 2018 in Shaanxi Province, China. Expert Rev Anti Infect Ther 2020;18:927-36.

23 Currie J, Lin W, Meng J. Addressing antibiotic abuse in China: an experimental audit study. J Dev Econ 2014;110:39-51.

24 Currie J, Lin W, Zhang W. Patient knowledge and antibiotic abuse: evidence from an audit study in China. $J$ Health Econ 2011;30:933-49.

$25 \mathrm{Xue} \mathrm{H}$, Shi Y, Huang L, et al. Diagnostic ability and inappropriate antibiotic prescriptions: a quasi-experimental study of primary care providers in rural China. J Antimicrob Chemother 2019;74:256-63.

26 Lam TP, Lam KF. What are the non-biomedical reasons which make family doctors over-prescribe antibiotics for upper respiratory tract infection in a mixed private/public Asian setting? J Clin Pharm Ther 2003:28:197-201

27 Zhang Z, Zhan X, Zhou H, et al. Antibiotic prescribing of village doctors for children under 15 years with upper respiratory tract infections in rural China: a qualitative study. Medicine 2016;95:e3803.

28 Chang J, Lv B, Zhu S, et al. Non-Prescription use of antibiotics among children in urban China: a cross-sectional survey of knowledge, attitudes, and practices. Expert Rev Anti Infect Ther 2018;16:163-72.

29 Jin Y, Lu Y, Lu P, et al. Influence of Demographic Characteristics on Antibiotics Use among Middle-Aged and Elderly People [in Chinese] Chin J Public Health 2014;30:1140-3.

30 Lam TP, Wun YT, Lam KF, et al. Differences in antibiotic use between patients with and without a regular doctor in Hong Kong. BMC Pharmacol Toxicol 2015;16:40.

31 Wun YT, Lam TP, Lam KF, et al. Are there differences in antibiotic use between the Recent-Immigrants from mainland China and the LocalBorn in Hong Kong? J Immigr Minor Health 2015;17:1177-84.

32 Wun YT, Lam TP, Lam KF, et al. The public's perspectives on antibiotic resistance and abuse among Chinese in Hong Kong. Pharmacoepidemiol Drug Saf 2013;22:241-9.

33 Liao CC, Chang YK, Chen HH, et al. Knowledge and use of antibiotics among people in Taiwan. Taiwan Journal of Public Health 2006;25:135-42.

34 Huang Y, Gu J, Zhang M, et al. Knowledge, attitude and practice of antibiotics: a questionnaire study among 2500 Chinese students. BMC Med Educ 2013;13:163.

35 Lu T, Li X. A Study on the Knowledge, Attitude and Behavior of Antibiotic Use among Students in Five Universities in Nanjing [in Chinese]. Acta Universitatis Medicinalis Nanjing 2016;16:274-80

36 Wang W, Wang X, Hu YJ, et al. The misconception of antibiotic equal to an anti-inflammatory drug promoting antibiotic misuse among Chinese university students. Int J Environ Res Public Health 2019;16:335

37 Huang Y, Chen R, Wu T, et al. Association between point-of-care CRP testing and antibiotic prescribing in respiratory tract infections: a systematic review and meta-analysis of primary care studies. $\mathrm{Br} \mathrm{J}$ Gen Pract 2013:63:e787-94.

38 Lu J, Wang X, Lin L, et al. The association between changes in external environment caused by migration and inappropriate antibiotic use behaviors among Chinese university students: a crosssectional study. Antibiotics 2019;8:200.

39 Lam TP, Lam KF. Why do family doctors prescribe antibiotics for upper respiratory tract infection? Int J Clin Pract 2003;57:167-9.

$40 \mathrm{Pan} \mathrm{H}$, Cui B, Zhang D, et al. Prior knowledge, older age, and higher allowance are risk factors for self-medication with antibiotics among university students in southern China. PLoS One 2012;7:e41314

41 Liao R. Investigation on the Impact of Parents' Cognitive Level of Antibiotics on Self-directed Use of Antibiotics in Pupils [in Chinese]. Practical Preventive Medicine 2013;20:42-5.

42 Yao Z, Zhou J, Li Y, et al. Prevalence of Self-Medication with Antibiotics in Kindergarten Children of Guangzhou City [in Chinese]. Chin J Public Health 2013;29:1485-7.

43 Lv B, Zhou Z, Xu G, et al. Knowledge, attitudes and practices concerning self-medication with antibiotics among university students in Western China. Trop Med Int Health 2014;19:769-79.
44 Lv B, Yang D, Fang Y, et al. Studying on the Behaviors and Influencing Factors of Self-Medication with Antibiotics among University Students in China [in Chinese]. Paper presented at: 2013 Annual Meeting of Pharmacy Management Professional Committee of Chinese Pharmaceutical Association and Academic Forum on "Medicine Safety and Scientific Development"; 2013/08/01, Beijing, China, 2013.

45 Li R, Xiao F, Zheng X, et al. Antibiotic misuse among children with diarrhea in China: results from a national survey. PeerJ 2016;4:e2668.

46 Li Y, Song Y, Shao R, et al. Determinants of Self-medication with Antibiotics among Residents in Nantong [in Chinese]. The Chinese Health Service Management 2016;33:39-41.

$47 \mathrm{Gu}$ J, Zhao J, Huang Y, et al. Use of antibiotics by urban and rural residents in Heilongjiang Province, China: cross-sectional study. Trop Med Int Health 2015;20:1815-22.

48 Zhu X, Pan H, Yang Z, et al. Self-Medication practices with antibiotics among Chinese university students. Public Health 2016;130:78-83.

49 Tian L, Dong J, Zeng Y, et al. Logistic Regression Analysis of Factors Affecting University Students' Antibiotics Self-Medication [in Chinese]. Science Popularity 2015;06:143.

50 Wang X, Lin L, Xuan Z, et al. Keeping antibiotics at home promotes self-medication with antibiotics among Chinese university students. Int J Environ Res Public Health 2018;15:687.

51 Sun C, Hu YJ, Wang X, et al. Influence of leftover antibiotics on selfmedication with antibiotics for children: a cross-sectional study from three Chinese provinces. BMJ Open 2019;9:e033679.

52 Dyar OJ, Yin J, Ding L, et al. Antibiotic use in people and pigs: a one health survey of rural residents' knowledge, attitudes and practices in Shandong Province, China. J Antimicrob Chemother 2018;73:2893-9.

53 Chang J, Xu S, Zhu S, et al. Assessment of non-prescription antibiotic dispensing at community pharmacies in China with simulated clients: a mixed cross-sectional and longitudinal study. Lancet Infect Dis 2019;19:1345-54.

54 Chen J, Wang Y, Chen X, et al. Widespread illegal sales of antibiotics in Chinese pharmacies - a nationwide cross-sectional study. Antimicrob Resist Infect Control 2020;9:12.

55 Chang J, Ye D, Lv B, et al. Sale of antibiotics without a prescription at community pharmacies in urban China: a multicentre crosssectional survey. J Antimicrob Chemother 2017;72:dkw519.

56 Wang X, Xuan Z, Storella TH, et al. Determinants of non-prescription antibiotic dispensing in Chinese community pharmacies from socio-ecological and health system perspectives. Soc Sci Med 2020;256:113035.

57 Jin C, Ely A, Fang L, et al. Framing a global health risk from the bottom-up: user perceptions and practices around antibiotics in four villages in China. Health Risk Soc 2011;13:433-49.

58 Reynolds L, McKee M. Factors influencing antibiotic prescribing in China: an exploratory analysis. Health Policy 2009;90:32-6.

59 Wei X, Deng S, Haldane V, et al. Understanding factors influencing antibiotic prescribing behaviour in rural China: a qualitative process evaluation of a cluster randomized controlled trial. J Health Serv Res Policy 2020;25:94-103.

60 Yin J, Dyar OJ, Yang P, et al. Pattern of antibiotic prescribing and factors associated with it in eight village clinics in rural Shandong Province, China: a descriptive study. Trans $R$ Soc Trop Med Hyg 2019;113:714-21.

61 Zhu E, Fors U, Smedberg Åsa. Understanding how to improve physicians' paradigms for prescribing antibiotics by using a conceptual design framework: a qualitative study. BMC Health Serv Res 2018;18:860.

62 Jiang H, Jin Y, Ye J, et al. An Analysis on Knowledge, Attitude and Practice Regarding Antibiotics Use among Community Residents in Hangzhou [in Chinese]. Preventive medicine 2017;29:978-82.

63 Zhong M, Yang W, Gao G, et al. Analysis on Antibiotic Knowledge and Uses among the Residents of Guangdong [in Chinese]. Chin J of PHM 2018;34:589-91.

64 Gong S, Qiu X, Song Y, et al. Effect of financially punished audit and feedback in a pediatric setting in China, within an antimicrobia stewardship program, and as part of an international accreditation process. Frontiers in Public Health 2016;4:99.

65 Liu C, Zhang X, Wan J. Public reporting influences antibiotic and injection prescription in primary care: a segmented regression analysis. J Eval Clin Pract 2015;21:597-603.

66 Liu C, Zhang X, Wang X, et al. Does public reporting influence antibiotic and injection prescribing to all patients? A clusterrandomized matched-pair trial in China. Medicine 2016;95:e3965. 
67 Shen X, Lu M, Feng R, et al. Web-Based Just-in-Time information and feedback on antibiotic use for village doctors in rural Anhui, China: randomized controlled trial. J Med Internet Res 2018;20:e53.

68 Wei X, Zhang Z, Hicks JP, et al. Long-Term outcomes of an educational intervention to reduce antibiotic prescribing for childhood upper respiratory tract infections in rural China: follow-up of a cluster-randomised controlled trial. PLoS Med 2019;16:e1002733.

69 Wei X, Zhang Z, Walley JD, et al. Effect of a training and educational intervention for physicians and caregivers on antibiotic prescribing for upper respiratory tract infections in children at primary care facilities in rural China: a cluster-randomised controlled trial. The Lancet Global Health 2017;5:e1258-67.

70 Yang L, Liu C, Wang L, et al. Public reporting improves antibiotic prescribing for upper respiratory tract infections in primary care: a matched-pair cluster-randomized trial in China. Health Res Policy Syst 2014;12:61.

71 China NBoSo. China statistical Yearbook 2019, 2019.

$72 \mathrm{KHTaW}$ B. Anticipating the future: appraising risk and uncertainty. In: Ray Crozier RR, Svenson O, eds. Decision making: cognitive models and explanations. 1 edn. London; : New York: Routledge, 1997.

73 Chan Y-H, Fan MM, Fok C-M et al. Antibiotics nonadherence and knowledge in a community with the world's leading prevalence of antibiotics resistance: Implications for public health intervention. Am $J$ Infect Control 2012;40:113-7.

74 Guan X, Tian Y, Song J, et al. Effect of physicians' knowledge on antibiotics rational use in China's county hospitals. Soc Sci Med 2019;224:149-55.

75 Liu C, Liu C, Wang D, et al. Determinants of antibiotic prescribing behaviors of primary care physicians in Hubei of China: a structural equation model based on the theory of planned behavior. Antimicrob Resist Infect Control 2019;8:23.

76 Wang J, Huang C, Li Z, et al. Knowledge and Behaviors of Antibiotic Use for Upper Respiratory Tract Infections among Parents of Young Children in Changsha City [in Chinese]. Chin J Public Health 2017:33:415-8.

77 Belongia EA, Naimi TS, Gale CM, et al. Antibiotic use and upper respiratory infections: a survey of knowledge, attitudes, and experience in Wisconsin and Minnesota. Prev Med 2002;34:346-52.

78 Kurniawan K, Posangi J, Rampengan N. Association between public knowledge regarding antibiotics and self-medication with antibiotics in Teling Atas community health center, East Indonesia. Medical Journal of Indonesia 2017;26:62-9.

79 Lum EPM, Page K, Nissen L, et al. Australian consumer perspectives, attitudes and behaviours on antibiotic use and antibiotic resistance: a qualitative study with implications for public health policy and practice. BMC Public Health 2017;17:799. 